\title{
Adult Anaplastic Ependymoma
}

National Cancer Institute

\section{Source}

National Cancer Institute. Adult Anaplastic Ependymoma. NCI Thesaurus. Code C8269.

An anaplastic ependymoma occurring in adults. 